\title{
Guia de orientação para \\ o desenvolvimento de projetos - GODP aplicado à prática projetual no design de moda
}

Giselle Schmidt Alves Díaz Merino

Doutora, Universidade do Estado de Santa Catarina/ gisellemerino@gmail.com Orcid: 0000-0003-4085-3561 / lattes

\section{Thiago Varnier}

Doutorando, Universidade Federal de Santa Catarina / thiagovarnier1@gmail.com Orcid: 0000-0003-0584-3077 / lattes

\section{Elen Makara}

Doutoranda, Universidade Federal de Santa Catarina / makaraelen@gmail.com Orcid: 0000-0001-9496-1862 / lattes 


\title{
Guia de orientação para o desenvolvimento de projetos - GODP - aplicado à prática projetual no design de moda
}

\begin{abstract}
RESUMO
A prática projetual do designer de moda está associada ao desenvolvimento de uma coleção, a qual passa por várias etapas até sua materialização e disponibilização no mercado. Assim, para coordenar sua criação, torna-se importante a aplicação de uma metodologia que auxilie e sistematize todo o processo de desenvolvimento do produto de vestuário. Desta maneira, este artigo tem como objetivo aplicar o Guia de Orientação para o desenvolvimento de Projetos (GODP), na prática projetual do Design de Moda. Para tanto, foi utilizado a pesquisa aplicada, qualitativa de cunho descritivo, por meio de uma pesquisa bibliográfica. Inicialmente realizou-se estudos referente ao processo de desenvolvimento de coleção de vestuário e na sequência esses procedimentos foram aplicados na metodologia do GODP. Os resultados apontam que o GODP aplicado a prática projetual do Design de moda, pode auxiliar os projetistas na compreensão das reais necessidades dos usuários e na gestão do processo operacional de desenvolvimento de coleção de vestuário. Contudo utilizar uma metodologia centrada no usuário, na prática projetual da moda, permite a obtenção de informações relevantes para o projeto, além de levantar dados sobre o público-alvo, o que favorece o conforto, a segurança e usabilidade das vestimentas.
\end{abstract}

Palavras-chave: Design de Moda. Design Centrado no Usuário. Desenvolvimento de Produto de Vestuário. 


\title{
Guidance for project development - GODP - applied to project practice in fashion design
}

\begin{abstract}
The designer's design practice is associated with the development of a collection, which goes through several stages until its materialization and availability in the market. Thus, in order to coordinate its creation, it is important to apply a methodology that helps and systematizes the entire process of developing the clothing product. In this way, this article aims to apply the Guidance Guide for the Development of Projects (GODP), in the design practice of Fashion Design. For that, the applied, qualitative descriptive research was used, through a bibliographical research. Initially, studies were carried out on the garment collection development process and following these procedures were applied in the GODP methodology. The results show that the GODP applied to the design practice of fashion design can help the designers to understand the real needs of the users and to manage the operational process of the collection of clothing. However, using a user-centered methodology in the fashion design practice allows the collection of information relevant to the project, as well as raising data about the target audience, which favors the comfort, safety and usability of clothing.
\end{abstract}

Keywords: Fashion Design. User-Centered Design. Product Development of Clothing. 


\title{
Orientación para el desarrollo de proyectos - GODP - aplicado a la práctica de proyectos en diseño de moda
}

\begin{abstract}
RESUMEN
La práctica de diseño del diseñador de moda está asociada con el desarrollo de una colección, que pasa por varias etapas hasta su materialización y disponibilidad en el mercado. Por lo tanto, para coordinar su creación, es importante aplicar una metodología que ayude y sistematice todo el proceso de desarrollo del producto de confección. De esta manera, este artículo tiene como objetivo aplicar la Guía de Orientación para el Desarrollo de Proyectos (GODP), en la práctica del diseño de Diseño de Moda. Para esto, se utilizó la investigación aplicada, cualitativa de naturaleza descriptiva, a través de una búsqueda bibliográfica. Inicialmente, se llevaron a cabo estudios sobre el proceso de desarrollo de la colección de ropa $y$, posteriormente, estos procedimientos se aplicaron a la metodología GODP. Los resultados muestran que el GODP aplicado a la práctica de diseño de Fashion Design puede ayudar a los diseñadores a comprender las necesidades reales de los usuarios y a gestionar el proceso operativo de desarrollo de la colección de ropa. Sin embargo, el uso de una metodología centrada en el usuario, en la práctica del diseño de moda, permite obtener información relevante para el proyecto, además de recopilar datos sobre el público objetivo, lo que favorece la comodidad, seguridad y usabilidad de la ropa.
\end{abstract}

Palabras clave: Diseño de moda. Diseño centrado en el usuario. Desarrollo de productos de indumentaria. 


\section{INTRODUÇÃO}

A prática projetual de um designer de moda geralmente está associada ao desenvolvimento de uma coleção, que se trata de um conjunto de produtos, de vestuário e acessórios, os quais apresentam uma relação ou unidade, entre si (TREPTOW, 2013). O desenvolvimento deste conjunto de produtos, em específico o vestuário, passa por várias etapas, que vão desde a identificação do problema, criação, materialização até a sua disponibilização no mercado. Para coordenar o desenvolvimento deste conjunto de produtos, em todas estas etapas, torna-se importante adotar uma forma de trabalho, que confere vantagens consideráveis em relação ao tempo despendido ao desenvolvimento do produto de vestuário; a redução de modificações, visto que estas acarretam custo elevado caso não aconteçam logo no início do desenvolvimento; e aumento da qualidade do produto sob diversos aspectos (BACK et al., 2008).

Na concepção de Rech (2002) os produtos desenvolvidos a partir de uma metodologia projetual apresentam um melhor desempenho se comparado aos desenvolvidos por métodos empíricos, além de serem obtidos em curto espaço de tempo, considerando conceito e cliente como pólos terminais do ciclo de desenvolvimento. Assim ao projetar uma coleção de moda se faz necessária, uma metodologia que auxilie, sistematize e principalmente coordene todo o processo de criação e desenvolvimento do produto de vestuário (TREPTOW, 2013).

Entretanto neste contexto é preciso ter o entendimento concreto sobre o perfil do usuário do produto em desenvolvimento, afinal é ele que fornecerá as diretrizes para o direcionamento e formulação do projeto (SANCHES, 2008). A indústria têxtil e de moda que não levar em 
consideração as informações do usuário no produto em desenvolvimento pode comprometer sua a qualidade (BOUERI, 2008). A este respeito, apesar de reconhecer a importância de considerar as necessidades do público alvo para o desenvolvimento de produtos de vestuários, poucas metodologias apresentam foco no usuário. Além disso, de acordo com Sanches (2008) o uso de metodologias de design para o desenvolvimento de produtos de moda ainda é pouco explorado por gestores empresariais e pelos cursos da área.

Assim, considera-se necessária uma metodologia centrada no usuário para a prática projetual da moda, que possa auxiliar os projetistas no processo de desenvolvimento de projeto de vestuário, considerando o usuário como ponto de partida. Além disso, minimizar as fragilidades no processo, com organização e sistematização, a fim de coordenar todas as informações do projeto. Portanto, este artigo tem como objetivo aplicar o Guia de Orientação para o desenvolvimento de Projeto - GODP (MERINO, 2014) - na prática projetual do Design de Moda.

A escolha pela metodologia GODP, justifica-se por utilizar uma abordagem de projeto centrado no usuário, ou seja, considerando as suas capacidades sensoriais, cognitivas e motoras, o que permite a aproximação dos projetistas às reais necessidades dos usuários. De acordo com Merino (2016, p. 12) "o GODP é uma metodologia configurada por oito etapas que se fundamentam na coleta de informações, o desenvolvimento criativo, a execução projetual, a viabilização e verificação final do produto". Além disso, propõe que cada momento de projeto (Inspiração - Ideação - Implementação) seja pensado em Blocos de Referência (Produto, Usuário e Contexto), os quais auxiliam na escolha de técnicas e ferramentas para desenvolver o projeto. 


\section{PROCEDIMENTOS METODOLÓGICOS}

Para atender ao objetivo do artigo, realizou-se a pesquisa de natureza aplicada, pela abordagem qualitativa com objetivo descritivo. De acordo com Lakatos e Marconi (2011) a pesquisa aplicada objetiva gerar conhecimentos para aplicação prática, buscando a solução de problemas específicos. Dessa forma, o artigo visa apresentar uma proposta de metodologia para a prática projetual do Design de Moda, com uma abordagem centrada no usuário, de modo a auxiliar os designers no processo de desenvolvimento de produtos de vestuário, bem como contribuir na organização e sistematização das informações de projeto. A abordagem qualitativa busca obter dados que serão transformados em informação, para que possam ser analisados e compreendidos (SAMPIERI; COLLADO; LUCIO, 2013) e, diante disso, busca-se compreender como os procedimentos de desenvolvimento de produtos de vestuário podem ser utilizados no GODP.

Quanto ao seu objetivo, é classificada como descritiva, propondo-se a descrever os procedimentos de desenvolvimento de produto de vestuário nos distintos momentos da metodologia do GODP. Segundo, Sampieri, Collado e Lucio (2013) os estudos descritivos buscam especificar as propriedades e características de processos, objetos ou qualquer outro fenômeno que se submeta a uma análise.

A pesquisa segmenta-se em duas fases: fase $1-$ Levantar; fase 2 - Relacionar e Descrever. Para a Fase 1 (Levantar) foi realizado o levantamento bibliográfico de estudos referentes ao processo de desenvolvimento de produto de vestuário, visando identificar as etapas, técnicas,

processos e procedimentos realizados para 0 
desenvolvimento do vestuário, caracterizando uma pesquisa exploratória de caráter descritivo. Este levantamento foi realizado em outubro e novembro de 2018, e ocorreu de forma assistemática com base em livros da área, teses e dissertações, bem como artigos de periódicos.

Posteriormente na fase 2 - (Relacionar e Descrever), os estudos levantados na fase 1, ou seja, as etapas, técnicas, processos e/ou procedimentos de PDP do vestuário, foram relacionados com a metodologia do GODP, com o intuito de demonstrar como o GODP pode ser aplicado à prática projetual no Design de Moda. Para isso, foi detalhado o percurso projetual do processo de desenvolvimento de produto de vestuário aplicado aos três momentos e oito etapas do GODP, abordando as especificidades da área da moda, ou seja, as técnicas, ferramentas e procedimentos utilizados para o desenvolvimento do vestuário, bem como a linguagem específica da área. Dessa forma, obteve-se um roteiro de orientação que possibilita compreender 0 funcionamento e operacionalização em cada etapa, na qual constam figuras sínteses que apresentam: o que é, o que fazer, e como fazer.

\section{PROCESSO DE DESENVOLVIMENTO DE PRODUTO DE VESTUÁRIO}

A partir dos estudos levantados na literatura, foi realizado uma linha do tempo dos PDP do vestuário, a qual está dividida em três categorias: teses e dissertações, artigos e livros, conforme pode ser observada na Figura 1. 
Figura 1. Linha do Tempo com estudos sobre PDP do vestuário.

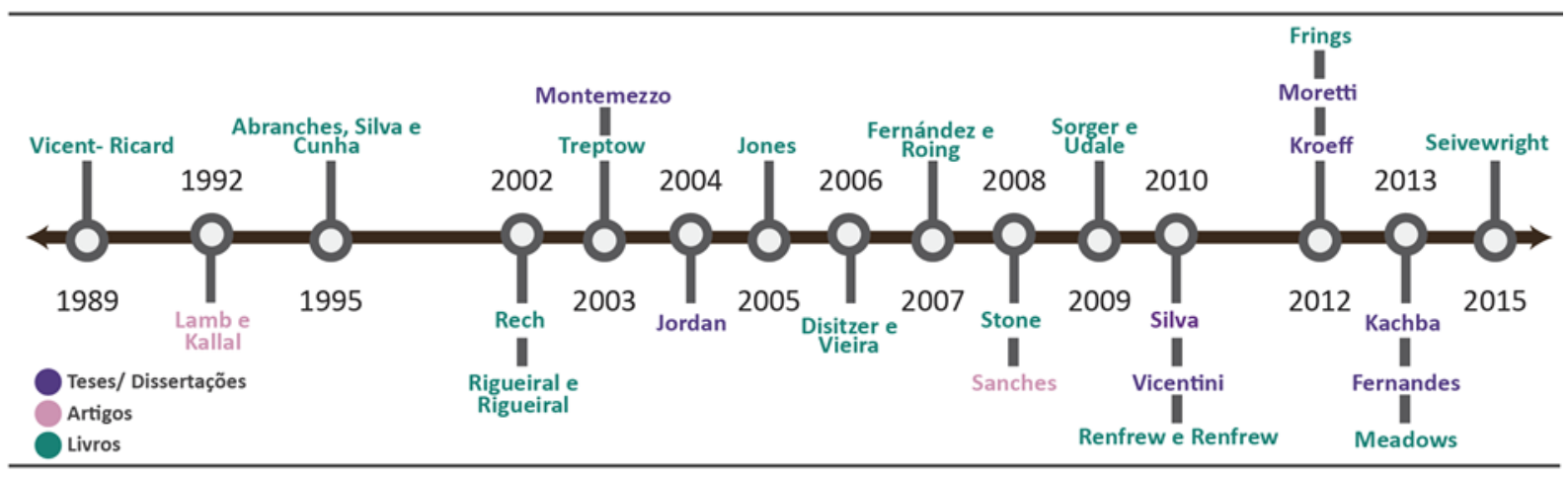

Fonte: Elaborada pelos autores (2019).

Em meio ao material encontrado, foi possível organizar o processo de desenvolvimento de produto de vestuário de cada autor em etapas, com suas respectivas ações. De acordo com Treptow (2013) o processo é dividido em quatro etapas: 1) Planejamento, 2) Design, 3) Desenvolvimento, 4) Promoção e Comercialização. Para Sanches (2008) o processo também é dividido em quatro etapas: 1) Planejamento, 2) Geração de Alternativas, 3) Avaliação e Detalhamento, e 4) Realização. Segundo Renfrew e Refrew (2010) o processo é dividido em quatro etapas: 1) Pesquisa, 2) Criação, 3) Desenvolvimento, 4) Edição e Apresentação. Já Montemezzo (2003) organiza-o em seis etapas: 1) Planejamento, 2) Especificação do Projeto, 3) Delimitação Conceitual, 4) Geração de Alternativas, 5) Avaliação e Elaboração, e 6) Realização. A Figura 2 apresenta uma síntese do PDP do vestuário. 
Figura 2. Síntese das etapas do PDP do vestuário.

\begin{tabular}{|l|c|c|c|c|}
\hline Autores & Planejamento/ Pesquisa & Design/ Criação & Desenvolvimento & Realização \\
\hline $\begin{array}{l}\text { Treptow } \\
(2013)\end{array}$ & Planejamento & Design & Desenvolvimento & $\begin{array}{l}\text { Promoção e } \\
\text { Comercialização }\end{array}$ \\
\hline $\begin{array}{l}\text { Sanches } \\
(2008)\end{array}$ & Planejamento & $\begin{array}{l}\text { Geração de } \\
\text { Alternativas }\end{array}$ & $\begin{array}{l}\text { Avaliação e } \\
\text { Detalhamento }\end{array}$ & Realização \\
\hline $\begin{array}{l}\text { Renfew e } \\
\text { Renfew (2008) }\end{array}$ & Pesquisa & Criação & Desenvolvimento & $\begin{array}{l}\text { Edição e } \\
\text { Apresentação }\end{array}$ \\
\hline $\begin{array}{l}\text { Montemezzo } \\
(2003)\end{array}$ & $\begin{array}{l}\text { Planejamento } \\
\text { Especificação do Projeto } \\
\text { Delimitação Conceitual }\end{array}$ & $\begin{array}{l}\text { Geração de } \\
\text { Alternativas }\end{array}$ & $\begin{array}{l}\text { Avaliação e } \\
\text { Elaboração }\end{array}$ & Realização \\
\hline
\end{tabular}

Fonte: Elaborada pelos autores (2019).

De modo geral o PDP de vestuário é iniciado na etapa Planejamento, denominada assim por Montemezzo (2003), Treptow (2013), Sanches (2008). Nesta etapa se buscam informações sobre o mercado, produtos e consumidores, que serão analisadas e servirão de bases para as futuras tomadas de decisões do processo (MONTEMEZZO, 2003). Durante o planejamento da coleção devem trabalhar juntos os setores de marketing, setor comercial, setor de criação e desenvolvimento, a gerência e/ou proprietários da empresa (MONTEMEZZO, 2003; TREPTOW, 2013). Ainda nesta etapa se determina o número de produtos da coleção, o mix de produtos, o mix de moda, define-se o tema da coleção e realiza-se a pesquisa de tendências. Por fim, elabora-se um cronograma da coleção com todas as atividades previstas (TREPTOW, 2013).

Na sequência, o designer de moda inicia a etapa de Design ou Criação da coleção, denominada assim por Treptow (2013) e Renfrew e Renfrew (2010) respectivamente. Também é conhecida como etapa de Geração de Alternativas (Sanches, 2008; Montemezzo, 2003), onde inicia se o traçado dos primeiros esboços ou desenhos de moda dos produtos de vestuário, levando em 
consideração todas as pesquisas e o planejamento da etapa anterior (TREPTOW, 2013). Ao finalizar as alternativas, realiza-se uma avaliação e consequentemente a seleção das melhores alternativas que irão compor a coleção (MONTEMEZZO, 2003; SANCHES, 2008).

Com os produtos de vestuários previamente definidos para compor a coleção, inicia-se uma etapa chamada de Desenvolvimento (TREPTOW, 2013; RENFREW; RENFREW, 2010) que envolve o preenchimento de ficha técnica, o desenvolvimento da modelagem, a confecção do protótipo, os testes de usabilidade e a aprovação final para a produção seriada.

Diante do PDP apresentado, percebe-se que os procedimentos podem ser sistematizados e organizados em etapas que auxiliem seu desenvolvimento, bem como coordene o grande volume de informações de projeto. Assim, o tópico a seguir apresenta o PDP do vestuário, aplicado no GODP, com o propósito de detalhar todo o percurso projetual aos três momentos e oito etapas da metodologia, a fim de favorecer uma sistematização e organização do PDP do vestuário.

\section{APLICAÇÃO DO GODP À PRÁTICA PROJETUAL NO DESIGN DE MODA}

O Guia de Orientação para o Desenvolvimento de Projetos - GODP -, proposto por Merino (2014), foi formulado a partir de literaturas de Design e outras áreas correlatas, ou seja, uma compilação de várias metodologias, que foram reestruturadas e adaptadas, para contemplar os aspectos intervenientes no desenvolvimento de projetos. Para tanto, seu objetivo é organizar e oferecer uma sequência de ações que permitam que 0 Design seja 
planejado de forma consciente, levando em consideração o maior número de aspectos possíveis, para responder aos objetivos do projeto. Além disso, apresenta flexibilidade e adaptabilidade o que permite ajustes no decorrer de todo o processo, de acordo com as particularidades de cada projeto (MERINO, 2016).

O GODP (Figura 3) é uma metodologia cíclica com abordagem centrada no usuário, configurada por oito etapas, divididas em três grandes momentos no processo de desenvolvimento de projeto: Momento Inspiração (etapa 1 - Oportunidade; etapa 0 - Prospecção; etapa 1 Levantamento de Dados); Momento Ideação (etapa 2 Organização e Análise; etapa 3 - Criação) e Momento Implementação (etapa 4 - Execução; etapa 5 Viabilização; etapa 6 - Verificação final) (MERINO, 2016).

Figura 3. Momentos e Etapas do Guia de Orientação para Desenvolvimento de Projeto.

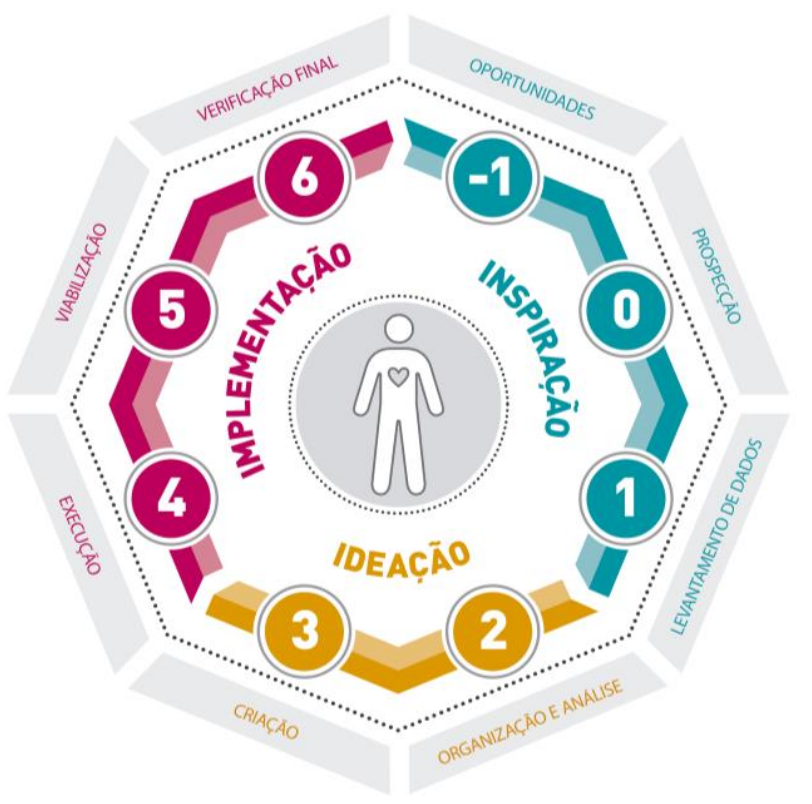

Fonte: Merino (2016, p. 15).

Percebe-se que um dos desafios da prática projetual é o grande volume de informações, considerando que se projeta 
algo (Produto), para alguém (Usuário) em algum lugar (Contexto). Dessa forma, ao Produto, Usuário e Contexto, Merino (2016) nomeou como Blocos de Referência (Figura 4), os quais organizam as informações durante todo o projeto, a respeito do que fazer e como fazer em cada bloco, dependendo da etapa, bem como auxiliam na escolha das técnicas e ferramentas para desenvolver o projeto.

Figura 4. Blocos de Referência (Produto, Usuário e Contexto).
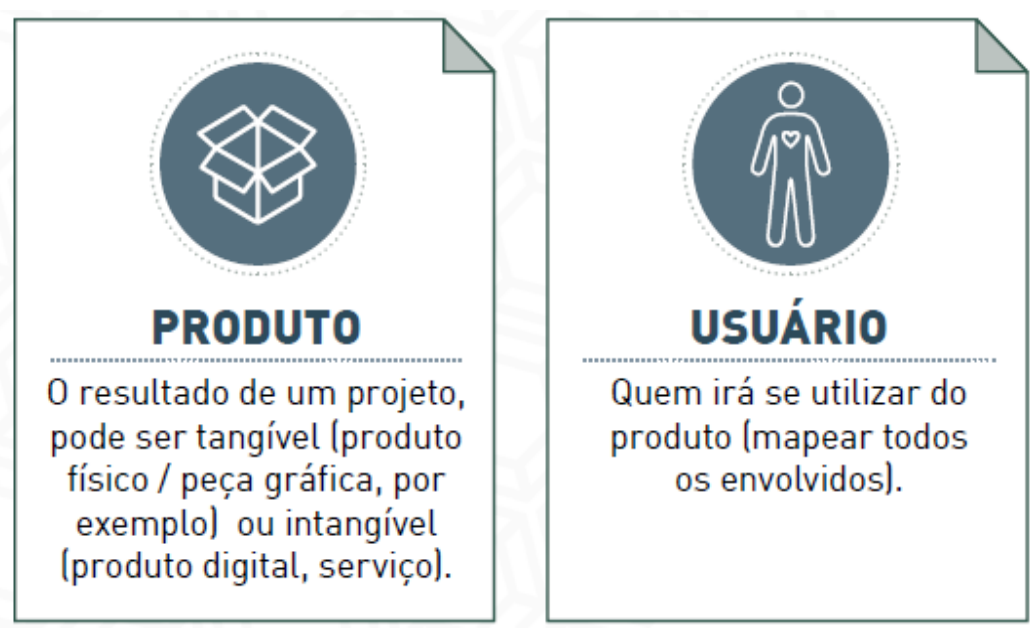

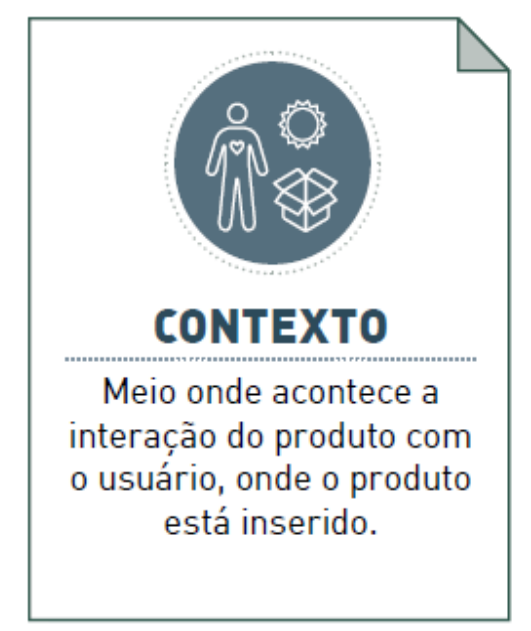

Fonte: Merino (2016, p. 20).

Devido sua flexibilidade e adaptabilidade, o GODP vem sendo aplicado no desenvolvimento de projetos em diversas áreas, a citar: design gráfico, design de produto, design de embalagens, em projetos da saúde, de reabilitação, bem como projetos de tecnologia assistiva, por meio de pesquisas de conclusão de curso (TAKAYAMA, 2017; CUNHA, 2017; ROSA, 2017; ANDRADE 2018; DUARTE, 2018) mestrado (VARNIER, 2019; HINNIG, 2018), doutorado (PICHLER, 2019; BLUM, 2018; GARCIA, 2017), dentre outros.

No que tange ao desenvolvimento de vestuário, os Blocos de Referência (Figura 5) referem-se: Produto - vestuário ou coleção que será desenvolvida; Usuário - público-alvo do 
vestuário, ou seja, aquele que utilizará as vestimentas; e o Contexto - ambiente onde o público alvo utilizará as vestimentas, o qual está relacionado diretamente à estação do ano a qual a coleção foi proposta e ao segmento de moda, a citar: moda casual, moda praia, moda festa, moda esportiva, entre outros.

Figura 5. Blocos de Referência para desenvolvimento de produto de vestuário.
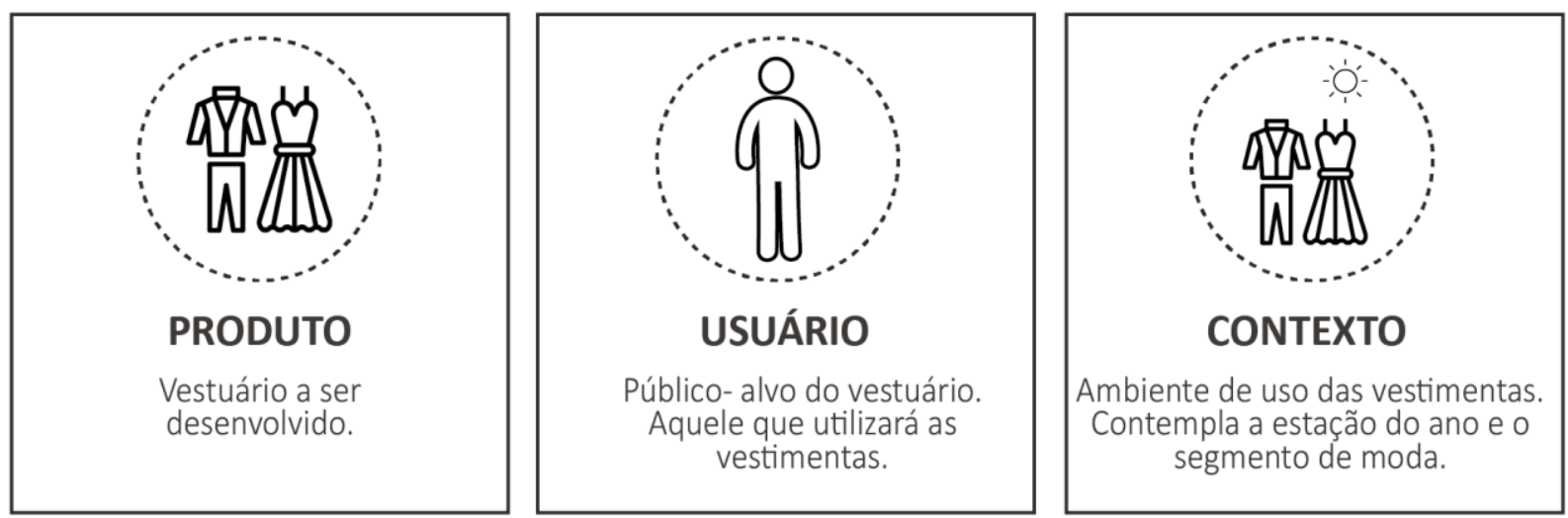

Fonte: Elaborada pelos autores, com base em Merino (2016).

A seguir será detalhado o percurso projetual do processo de desenvolvimento de produto de vestuário aplicado aos três momentos e oito etapas do GODP.

\subsection{Momento Inspiração}

É o momento em que a equipe de projeto deve realizar as coletas de informações em todas as fontes possíveis. Está organizado em três etapas (-1: Oportunidades; 0 : Prospecção e 1: Levantamento de dados), as quais serão apresentadas a seguir.

\subsubsection{Etapa -1 - Oportunidades}


Nesta etapa são verificadas as oportunidades do mercado/setores, conforme o produto a ser avaliado, considerando um panorama local, nacional e internacional e a atuação na economia. Desta forma, são evidenciadas as necessidades de crescimento do setor e outras conforme o produto (MERINO, 2016, p. 13).

Para o desenvolvimento do produto de vestuário, esta etapa segue a mesma definição de Merino (2016). Ao se referir a produto Montemezzo (2003), afirma que uma característica essencial das empresas que produzem vestuário é a diversificação e renovação de em curtos espaços de tempo.

Diante deste contexto, Frings (2012) aborda que os designers precisam prever cenários, ou seja, antecipar os desejos e necessidades dos clientes. Para tanto, ressalta as seguintes atividades: (1) estudar as condições de mercado, de modo a compreender como o comportamento de compra do consumidor é influenciado pela sociedade, economia, tecnologia e meio ambiente; (2) observar o estilo de vida do público; (3) pesquisar as estatísticas de venda; (4) avaliar as coleções anteriores ; (5) pesquisar as publicações de moda, catálogos, e serviços de design; (6) observar o que as pessoas estão usando; e (7) manter-se atualizado com os acontecimentos atuais, as artes, humor ou clima do público. Assim, na figura 6, propõem-se as atividades para esta etapa. 
Figura 6. Momento Inspiração - Etapa -1 - Oportunidades.

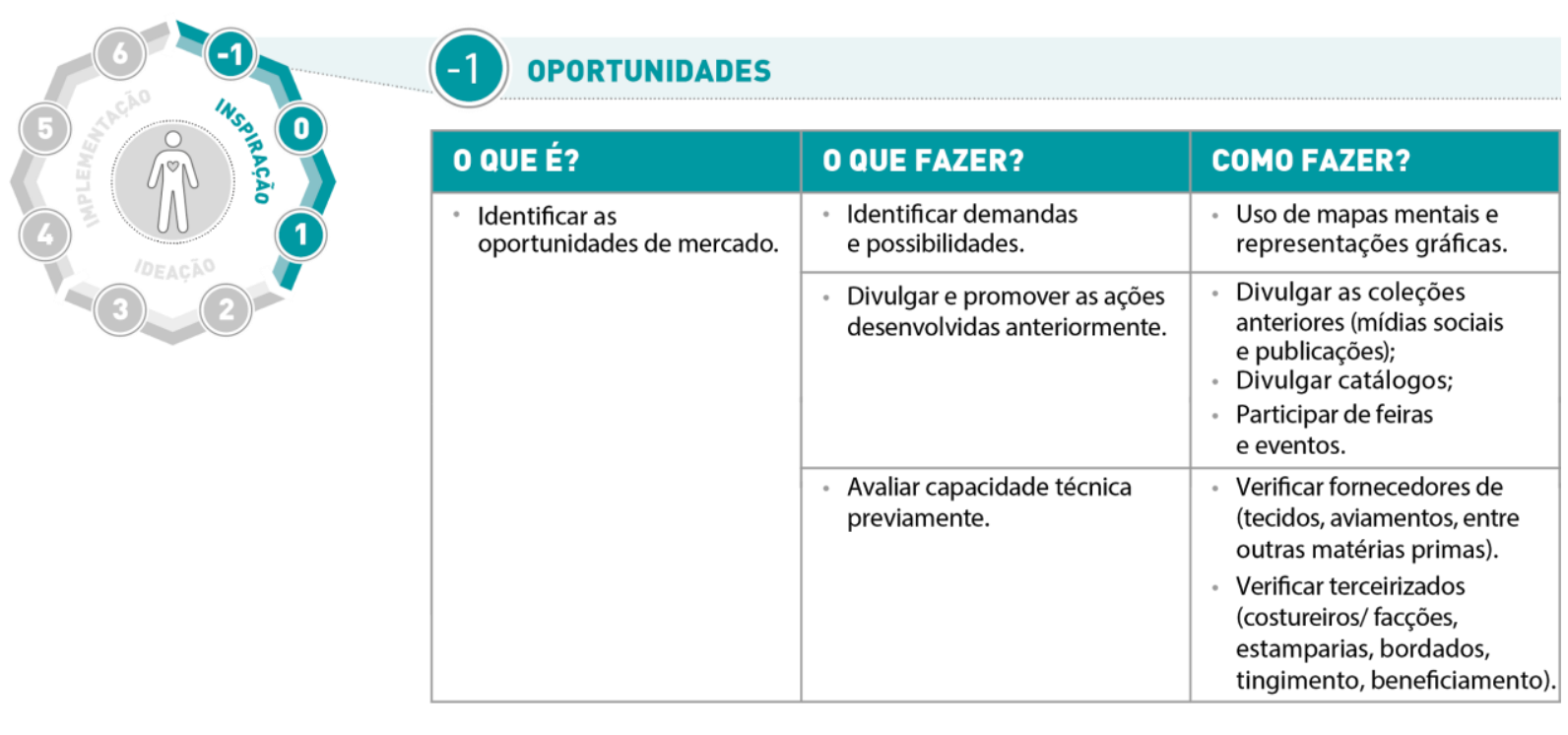

Fonte: Elaborada pelos autores (2019).

\subsubsection{Ełapa 0 - Prospecção}

"Nesta etapa, após a verificação das oportunidades é definida a demanda/problemática central que norteará o projeto" (MERINO, 2016, p. 13). Além disso, definir os Blocos de Referência (Produto, Usuário e Contexto) os quais guiaram todo o processo a partir da etapa seguinte. Para o desenvolvimento do produto de vestuário, segue a mesma definição de Merino (2016). Para detectar uma demanda que poderá ser transformada na problemática que norteará o projeto de design, uma empresa de moda pode realizar análises das informações obtidas com o mercado e histórico de vendas de produtos anteriores (MONTEMEZZO, 2003). As análises e discussões sobre um novo projeto de coleção se iniciam com uma reunião de planejamento, na qual, tratando-se de uma empresa de moda, devem estar presentes representantes do setor de criação, comercial, marketing e proprietários da empresa. Nesta reunião se 
define o cronograma, tamanho da coleção, mix de produtos, mix de moda, cronograma e briefing (TREPTOW, 2013).

No que tange o cronograma, este deve informar todas as atividades prevista para o desenvolvimento da coleção e suas respectivas datas de execução, de modo que a coleção fique pronta no tempo correto de venda, ou seja, na estação do ano correspondente. Para a elaboração do cronograma é importante conhecer os prazos de entrega dos serviços terceirizados (TREPTOW, 2013).

Durante a reunião de planejamento também se discute sobre o mix de produtos, que se refere ao número de peças que irão compor a coleção, e o mix de moda, que trata da proporção das peças da coleção que apresentam maior ou menor conteúdo de moda (MONTEMEZZO, 2003). Ao discutir o dimensionamento da coleção, ou seja, seu tamanho e as variedades dos produtos, Sanches (2008) destaca que além de levar em consideração as necessidades, desejos dos consumidores e informações de tendências de moda, devese realizar pesquisa sobre materiais, tecnologias e capacidade produtiva. Assim, para auxiliar o designer de moda e o processo de desenvolvimento da coleção elaborase um briefing - documento que contém informações sobre as restrições e condições da coleção, sobre os aspectos do segmento ou ocasião de uso, da estação, do público-alvo, dos materiais e tecidos, dos custos, do tema, entre outros (SEIVEWRIGHT, 2015).

De acordo com Renfrew e Renfrew (2010), para o desenvolvimento da coleção o designer necessita desenvolver o tema da coleção, o qual pode ser aprimorado a partir de uma pesquisa, independentemente do local, da época ou da estação. Portanto podem ser usadas imagens e desenhos em painéis de inspiração ou conceituais. Neste sentido, Frings (2012) salienta que manter o tema de uma 
coleção propicia ao designer incorporar uma combinação agradável de todos os elementos (cor, tecido, linha e forma) em cada peça. Assim, entende-se que o designer deve estudar profundamente o tema a fim de comunicar o conceito de maneira simples e clara (FERNÁNDEZ; ROING, 2007). Afinal, o tema é a essência de uma boa coleção, pois é o que a torna única e pessoal (SEIVEWRIGHT, 2010).

Cabe salientar, que Treptow (2013) aborda que toda coleção implica em planejamento, conhecimento de tendências e de mercado consumidor e deve possuir unidade e coordenabilidade. Mediante tais informações é importante identificar um nicho de mercado em torno de um determinado estilo de vida ou necessidade, ou seja, a parte do mercado que pretende atender, ou que não é servido adequada ou inteiramente por outros fabricantes (FRINGS, 2012). Dessa forma, a Figura 7 apresenta a síntese das atividades para esta etapa.

Figura 7. Momento Inspiração - Etapa 0 - Prospecção.

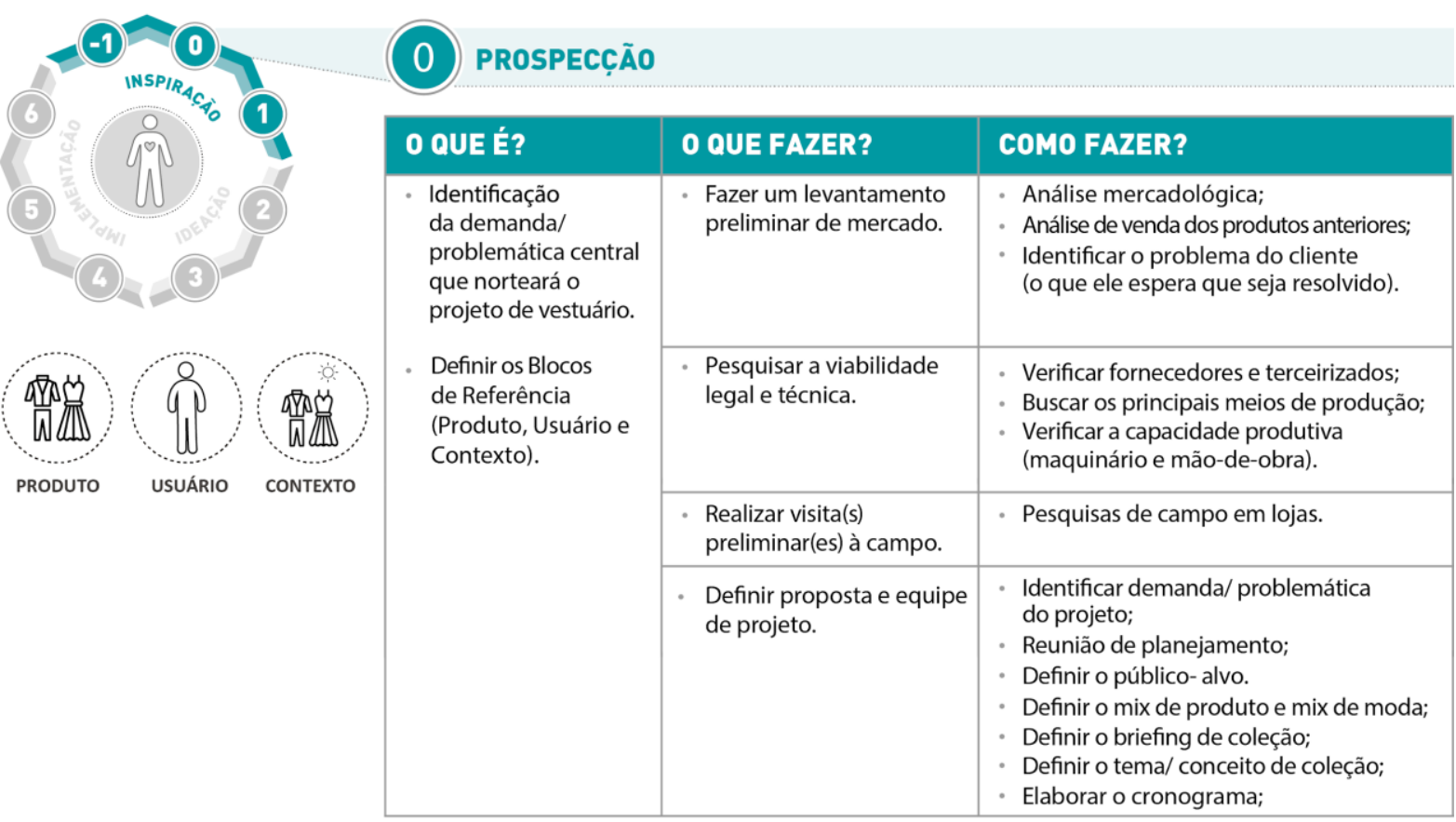

Fonte: Elaborado pelos autores (2019). 


\subsubsection{Etapa 1 - Levantamento de Dados}

Nesta etapa são desenvolvidas as definições do
projeto com base em um levantamento de
dados em conformidade com as necessidades e
expectativas do usuário, que contemplam os
quesitos de usabilidade, ergonomia e
antropometria, dentre outros, bem como as
conformidades da legislação que trata das
normas técnicas para o desenvolvimento dos
produtos (MERINO, 2016, p. 13).

Para o desenvolvimento do produto de vestuário, nesta etapa às necessidades e expectativas do usuário, referem-se ao público alvo da coleção. O designer deve estar atento ao comportamento do mercado, as novas tecnologias e tendências de moda. A pesquisa não é um processo temporário, por isso, todo designer de moda deve consultar diferentes fontes de informação, desde visita à campo em lojas concorrentes e dos fornecedores, observação nas ruas e vitrines, participação em feiras e desfiles, viagens e pesquisas bibliográficas em revistas, livros e sites. Ao final é necessário interpretar e adaptar as informações ao contexto da empresa e do público-alvo (TREPTOW, 2013).

Entre os tipos de pesquisas que devem ser realizadas pelo designer de moda destaca-se a pesquisa de comportamento do público-alvo, comparativa de mercado, tecnológica, vocações regionais, tendências e de tema de coleção. A pesquisa de comportamento acompanha os hábitos de consumo do público-alvo e seus interesses atuais com relação aos lugares que frequenta, ídolos da música, cinema, televisão e outros temas de interesse (TREPTOW, 2013). Vicentini (2010) explica que durante a realização da pesquisa sobre o público-alvo, este deve ser compreendido com o máximo de precisão, por meio do levantamento de 
características básicas, tais como sexo, faixa etária, características físicas, poder aquisitivo, localização geográfica, bem como informações mais profundas sobre o estilo de vida de seu público, os locais que frequenta e o possível uso que é dado ao produto, visto que o vestuário deve se adaptar as tarefas que o usuário executa ao longo do dia. A pesquisa sobre o público-alvo também pode ocorrer por meio da observação da interação entre produto e usuário, em lugares públicos, para conferir posturas e movimentos executados pelo usuário do produto. Para o autor, esta prática não é muito usual em empresas de moda, mas importante para inserir os aspectos ergonômicos ao produto e aprimorar a modelagem.

A pesquisa comparativa de mercado refere-se a pesquisa em lojas concorrentes a fim de verificar o estilo, a qualidade e o preço dos produtos que já estão no mercado (TREPTOW, 2013). Estas pesquisas devem ser realizadas constantemente, a fim de compreender o mercado-alvo identificando os seus hábitos de compra e preferências (FRINGS, 2012). A pesquisa tecnológica trata de acompanhar as inovações de técnicas e maquinários que podem ser utilizados no desenvolvimento da coleção. Esta pesquisa, é favorecida por meio do contato com os fornecedores, que apresentam aos designers as inovações, oportunizados em visitas às feiras e eventos do setor têxtil e de confecção, ou quando fornecedores agendam visitas às empresas de confecção para apresentar os novos produtos. A pesquisa de vocações regionais destina-se a encontrar materiais e técnicas alternativas para inserir na coleção, com a intenção de desenvolver produtos diferenciados com característica de alguma região (TREPTOW, 2013).

Fernandes (2013) destaca a pesquisa de tendências como início do processo de pesquisa de moda, e a sua 
profundidade está relacionada com os recursos disponíveis pela empresa. Após sua realização, faz-se sua análise, cujo objetivo é selecionar somente o que é significativo para o nicho de mercado. Meadows (2013) aponta que as pesquisas de tendências podem vir de várias fontes, a citar: internet, revistas internacionais, revistas nacionais, birôs de moda, book de tendências, viagens (moda rua, vitrines), novelas, palestras, entre outras. A pesquisa de tema, refere-se a coleta de informações sobre a inspiração escolhida, as quais auxiliam criativamente no desenvolvimento da coleção, sendo que o tema definido pode ou não estar de acordo com as pesquisas de tendências (TREPTOW, 2013).

A partir do momento que se tem o conhecimento do usuário, das tendências de moda, da imagem de marca e metas comerciais da empresa, se define o conceito geral ou tema dos produtos, o qual, é responsável por orientar a integração e harmonia do conjunto de produtos lançados simultaneamente (MONTEMEZZO, 2003). O projeto de produto de moda envolve o desenvolvimento de vários produtos ao mesmo tempo, e o conceito gerador consegue os unir por uma ideia central, proporcionando a coerência da linguagem (SANCHES, 2016). Assim, a Figura 8 apresenta a síntese das atividades para esta etapa. 
Figura 8. Momento Inspiração - Etapa 1 - Levantamento de dados.

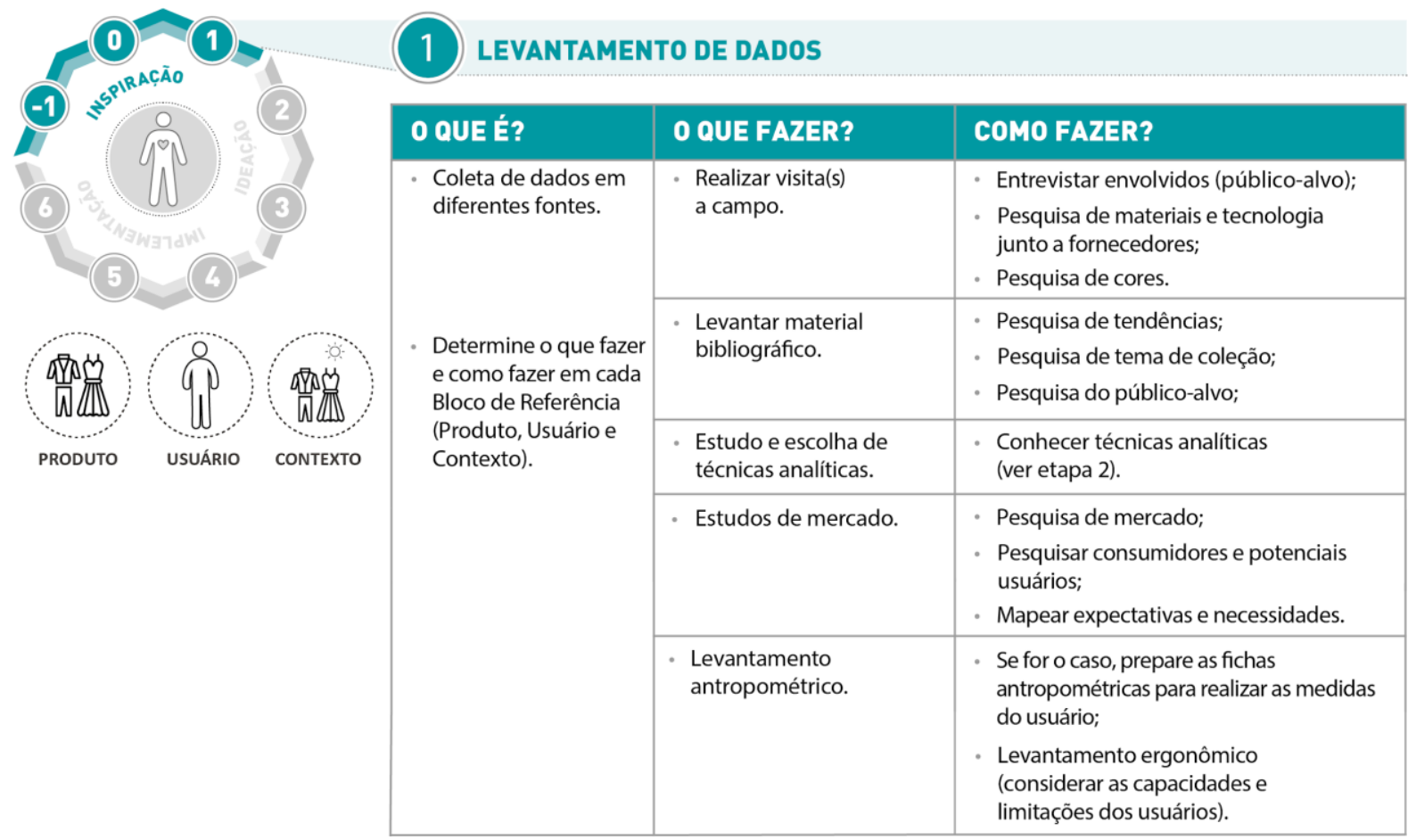

Fonte: Elaborada pelos autores (2019).

\subsection{Momento Ideação}

Este é o momento em que a equipe de projeto transforma as informações e todos os dados coletados em ideias de projeto. Está organizado em duas etapas (2: Organização e Análise e 3: Criação), as quais serão apresentadas a seguir.

\subsubsection{Etapa 2 - Organização e Análise}

Após o levantamento das informações, na forma de dados, os mesmos são organizados e analisados. Neste momento podem ser utilizadas técnicas analíticas que permitirão definir as estratégias de projeto (MERINO, 2016, p. 14). 
Para o desenvolvimento do produto de vestuário, esta etapa segue a mesma definição de Merino (2016). É o momento de organizar os dados coletados, ou seja, etapa para realizar os painéis imagéticos (digitais ou manuais), do público alvo ou lifestyle, painéis de inspiração, tema de coleção, definição da cartela de cores, materiais, tecidos, aviamentos, análises semânticas (diacrônicas, sincrônicas, entre outras), bem como o momento de pensar nos fatores humanos para o projeto de coleção. Também é o momento de realizar as diretrizes ou estratégias para a criação e rever o cronograma.

A prática projetual do design de moda pode ser auxiliada por ferramentas de síntese visual, em especial os painéis imagéticos, que favorecem a construção do pensamento no desenvolvimento de novos produtos. As pesquisas de imagens para elaboração destes painéis devem ser realizadas levando em consideração o universo do usuário, o posicionamento mercadológico da empresa e os recursos técnico-produtivos (SANCHES, 2016). Nesta fase do desenvolvimento de organização e análise da coleção é comum o designer de moda explicar o tema da nova coleção para a equipe por meio da elaboração de painéis, utilizando imagens ou desenhos, que expressam este tema com referências estéticas e simbólicas (MONTEMEZZO, 2003; RENFREW E RENFREW, 2010). Fernandes (2013) explica que os temas de coleção orientam a equipe de design criativo na seleção de materiais bem como no estilo das novas peças que serão desenvolvidas durante a estação.

Após a escolha do tema é definida a cartela de cores, a qual além de possuir relação com o tema da coleção também deve estar adequada aos usuários. Ainda se define os materiais, tecidos e aviamentos, e a partir da escolha da matéria-prima é possível prever o custo da peça e se ela 
poderá ser produzida e vendida na faixa de preço que o usuário está disposto a pagar (TREPTOW, 2013).

Uma coleção pode apresentar um produto âncora, um best-seller da coleção anterior com mudança na cor, no tecido, silhuetas, comprimentos, tratamentos das mangas, decotes e outros detalhes (FRINGS, 2012). Assim é possível realizar análises semânticas (sincrônicas para o estudo da vestimenta no contexto atual, e análise diacrônicas para compreender o histórico da vestimenta).

Neste momento é importante pensar nos fatores humanos que irão influenciar na vestimenta, ou seja, as questões de usabilidade, conforto e funcionalidade das peças, determinando os requisitos de projetos para 0 desenvolvimento do produto de vestuário. Boueri (2008) salienta que as características que definem grupos de consumidores são a idade, o gênero, a forma do corpo, a raça, a capacidade física e a atividade exercida. Neste sentido, Jones (2005), Sanches (2008) e Martins (2008) apontam que além dos diversos fatores estéticos que estão atrelados ao desenvolvimento do produto de vestuário, também devem ser analisados os requisitos práticos que possibilitam sua efetiva usabilidade. Boueri (2008) afirma que para a vestimenta se acomodar e se movimentar harmoniosamente, se faz necessário que os designers de moda tenham conhecimento sobre as dimensões e os movimentos corporais, a anatomia e a estrutura do corpo do usuário.

De acordo com Iida e Guimarães (2016) a usabilidade é a qualidade ergonômica que permite adequação entre usuário e produto, facilitando movimentação (biomecânica e cognição), conforto (práticas de uso), facilidade de uso e segurança. Neste sentido, Varnier e Merino (2017) apontam que os fatores humanos tornam o produto de vestuário 
seguro, prático, confortável e de fácil manejo, mantendo uma efetiva relação de uso com o ser humano, transformando-os em artefatos agradáveis e prazerosos durante o uso (MARTINS, 2008).

Por fim, nesta etapa, é importante revisar o cronograma dos prazos das atividades previstas para atender às datas de envio das mercadorias, afinal, o trabalho em uma nova coleção começa aproximadamente 8 a 10 meses antes da temporada de venda (FRINGS, 2012). A Figura 9, apresenta a síntese dessa etapa, e recomenda-se que essa organização também seja realizada pelos Blocos de Referência (Produto, Usuário e Contexto).

Figura 9. Momento Ideação - Etapa 2 - Organização e análise.

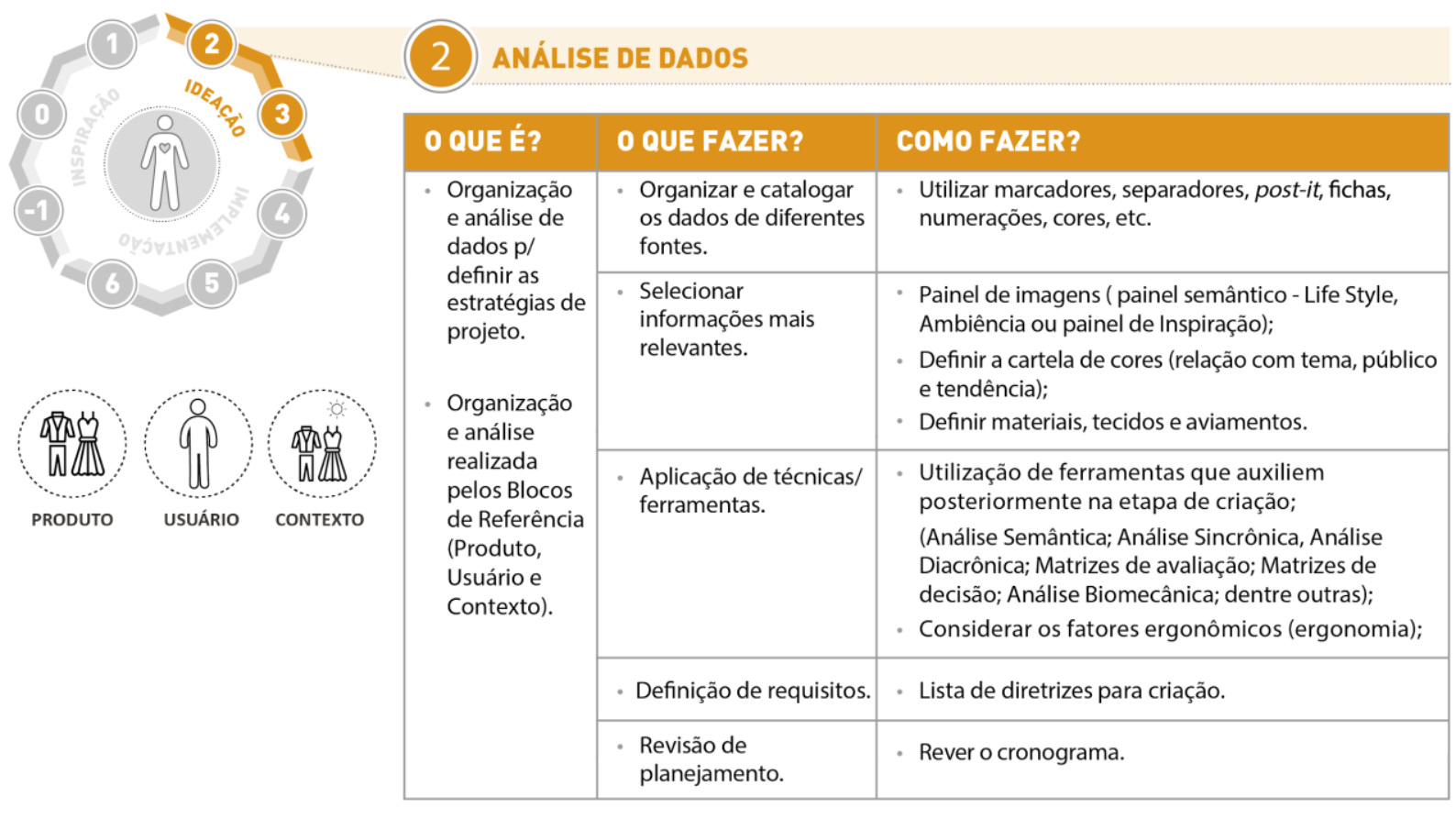

Fonte: Elaborada pelos autores (2019).

\subsubsection{Etapa 3 - Criação}

De posse das estratégias de projeto, são definidos os conceitos globais do projeto, sendo geradas as alternativas preliminares e 
protótipos. Estas são submetidas a uma nova análise se utilizando de técnicas e ferramentas, permitindo a escolha daquelas que respondem de melhor forma as especificações de projeto e atendimento dos objetivos (MERINO, 2016, p. 14).

No desenvolvimento do produto de vestuário, esta etapa refere-se às estratégias de projeto de coleção, onde será definido o tema de coleção e subtemas, para posteriormente gerar as alternativas preliminares (esboços) e os croquis finais (Figura 10). Vale salientar que nesta etapa o GODP aponta a utilização de ferramentas que auxiliem na escolha das alternativas que melhor atendem às especificações e objetivos do projeto. A etapa de criação, inicia com a exploração do tema da coleção para estabelecer uma uniformidade entre os modelos, de modo que eles possam conversar entre si (DISITZER; VIEIRA, 2006). Frings (2012) corrobora que o designer deve incorporar uma combinação agradável de todos os elementos, a citar: cor, tecido, linha e forma, em cada peça, a fim de manter o tema da coleção. Para tanto utilizam-se dos painéis visuais com amostras de cores e tecidos, esboços de ideias e recortes de revistas que transmitem o tema da coleção.

Para Fernández e Roing (2007), este é o momento de iniciar o desenho da coleção, onde deve ser expressado tanto a inspiração como o tema, visto que esta união aglutina o desenvolvimento do produto de moda. Com o tema da coleção, cartela de cores, tecidos e aviamentos definidos se inicia a criação das propostas para a coleção (TREPTOW, 2013). Esta fase é marcada pelo início da materialização das referências anteriores em produtos de vestuário, ou seja, o momento em que as ideias começam a tomar formas concretas (MONTEMEZZO, 2003). Para Sanches (2008) é a hora de transformar todos esses 
conceitos em elementos compositivos para a configuração dos produtos, além da definição de materiais e tecnologias. Ainda, Fernandes (2013) e Treptow (2013) abordam que concomitante aos desenhos dos modelos das peças, também são desenvolvidos modelos de bordados, estampas e desenhos técnicos.

Montemezzo (2003) aborda que as ferramentas de desenho, informática e modelagem tridimensional (moulage ou draping), são essenciais, por meio das quais, o designer poderá expressar e elaborar suas ideias e conceitos para novos produtos. Treptow (2013) aborda que os esboços podem ser produzidos à mão livre ou com o uso de programas de desenho em computadores, por exemplo o Corel Draw, o Photoshop e o Illustrator.

Figura 10. Momento Ideação - Etapa 3 - Criação.

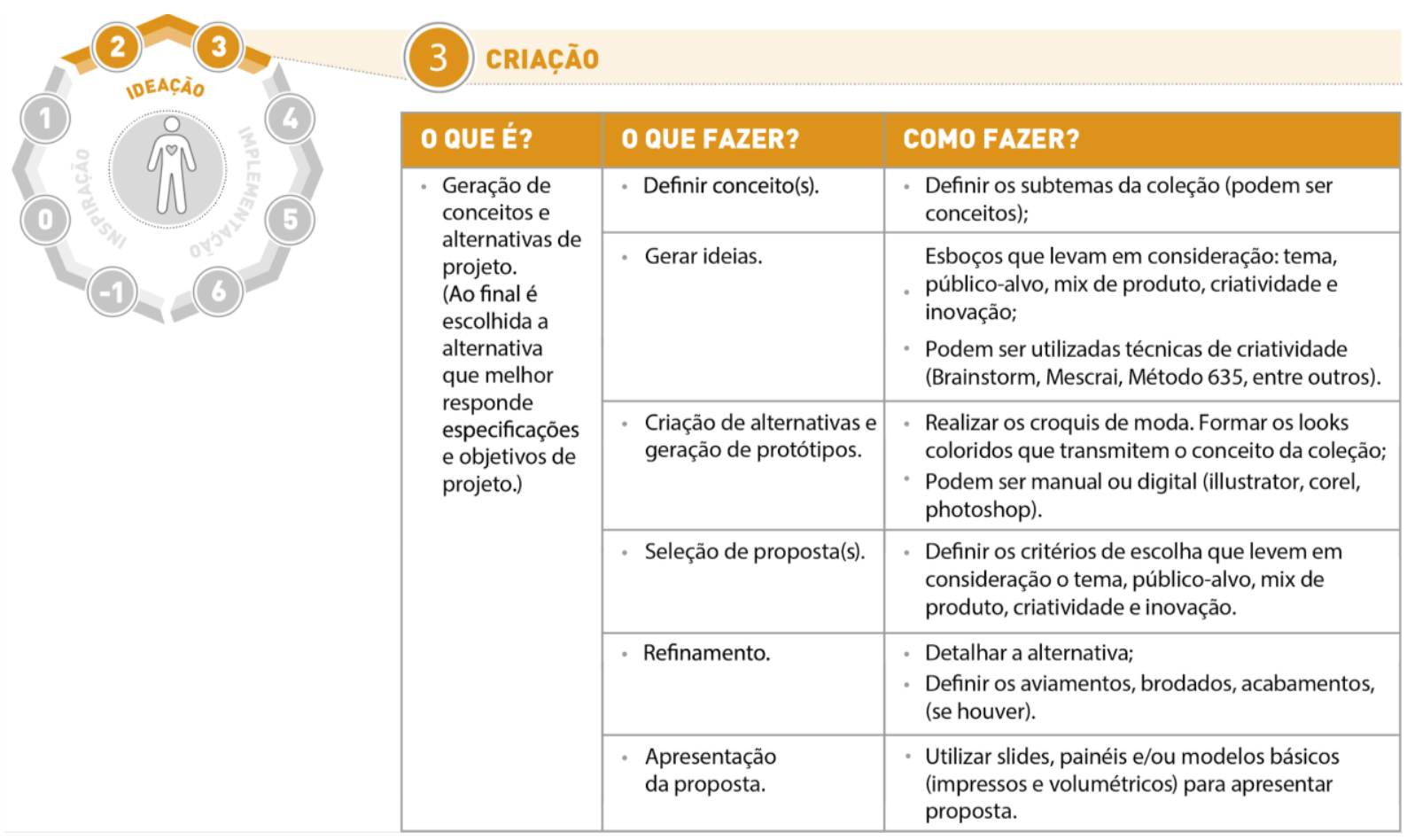

Fonte: Elaborado pelos autores, 2019. 


\title{
4.3 Momento Implementação
}

Este é o momento em que a equipe de projeto realiza a materialização das ideias. Está organizado nas três etapas (4: Execução; 5: Viabilização e 6: Verificação final), as quais serão apresentadas a seguir.

\subsubsection{Ełapa 4 - Execução}

\begin{abstract}
Nesta etapa, considera-se o ciclo de vida do produto em relação às propostas. A partir destas são desenvolvidos protótipos (escala) e/ou modelados matematicamente, para posteriormente elaborar o (s) protótipo (s) funcionais do (s) escolhido (s), para os testes (de usabilidade, por exemplo) (MERINO, 2016, p. 14).
\end{abstract}

Para o desenvolvimento do produto de vestuário, esta etapa refere-se à seleção das melhores alternativas de projeto, do ponto de vista técnico, ou seja, consistentemente. Ainda é realizado o desenvolvimento das fichas técnicas de modo a detalhar os itens de produção, bem como o desenvolvimento dos moldes (modelagem da peça). Assim, é possível desenvolver (prototipar) a peça piloto para os testes (usabilidade, ergonômicos) com o público alvo da coleção, conforme pode ser observado na Figura 11. 
Figura 11. Momento Implementação - Etapa 4 - Execução.

\begin{tabular}{|l|l|l|}
\hline OUE É? & QUE FAZER? & COMO FAZER? \\
\hline
\end{tabular}

Fonte: Elaborada pelos autores (2019).

Nesta etapa seleciona-se a melhor alternativa, ou melhores, no caso de um conjunto de produtos (coleção), sob os critérios da especificação do projeto (MONTEMEZZO, 2003). Para isso, Treptow (2013) aborda a necessidade de avaliar a proposta da coleção em uma reunião de definição, a fim de analisar a viabilidade de produção, a possibilidade de redução de custos ou como tornar o produto mais atraente ao consumidor. A partir dos modelos aprovados nesta reunião, é realizada e desenvolvida a ficha técnica, a qual deve conter 0 desenho técnico com informações precisas de como a peça deverá ser confeccionada.

Fernandes (2013) afirma que deve ser desenvolvida uma ficha técnica preliminar para cada modelo contendo informações sobre os tecidos, estampas, aviamentos, costura e acabamentos, e, além disso, realizar cálculo de custos preliminares. A este respeito, Frings (2012) ressalta a necessidade de registrar as seguintes informações: (1) data em que a peça foi desenhada; (2) temporada de venda; (3) tamanhos; (4) referência; (5) breve descrição de peça; (6) desenho técnico (7) cores ou combinações de cores; (8) amostras do tecido usado na peça; (9) descrição de 
materiais (10) largura do marcador, geralmente dois centímetros menor do que o tecido; (11) informações sobre detalhes e acabamentos; (12) custos de mão de obra para montagem da grade de numeração, marcação, corte, costura, acabamento, tingimento e lavagem, os quais podem ser listados na planilha de custos separada, elaborada pelo departamento de custo.

Ao finalizar as fichas técnicas, é o momento de os desenhos técnicos seguirem para o setor da modelagem, onde são desenvolvidos os moldes reproduzindo planificadamente as formas e medidas do corpo humano, de acordo com a tabela de medidas do público-alvo da empresa. Segundo Treptow (2013, p. 152), "cabe a cada empresa conhecer seu público-alvo e desenvolver ou adaptar tabelas de medidas, de forma a melhor atender à sua clientela". Ao finalizar os moldes é o momento de transformar as ideias em produtos físicos, ou seja, é realizada a confecção do protótipo (FERNANDES, 2013). O protótipo deverá ser confeccionado e testado em modelos a fim de verificar o caimento e conforto (TREPTOW, 2013). Além disso, durante a prototipagem são analisadas questões relacionadas à produção, como "adaptação de aparelhos para aumentar a eficiência de produção, análise do comportamento do tecido na máquina, e definir os padrões de costura e acabamento do artigo final" (FERNANDES, 2013, p. 112).

A este respeito, Sanches (2008) salienta a importância da experimentação de quesitos de conforto, manutenção, vestibilidade e segurança, para evitar a insatisfação do usuário, considerando que o bem-estar psicológico está intrinsecamente ligado à boa adaptação do vestuário ao corpo. Assim, estes testes de adequação de uso favorecem a descrição do conforto e a modelagem da peça. 
Ao finalizar a confecção das peças, a última ação desta etapa é a realização da análise e aprovação de estilo, que leva em consideração o alinhamento com o tema da coleção e a aparência do produto (FERNANDES, 2013). Após a aprovação segue para a graduação acompanhadas de uma ficha técnica, onde todas as peças serão replicadas prestando atenção nas amostras utilizadas, nos requisitos dos materiais e na sequência operacional de costura para compor o mostruário que guiará a produção seriada (TREPTOW, 2013).

A programação da produção envolve a compra de tecidos e aviamentos, e deve ser programada com base na previsão da demanda ou dos pedidos dos clientes lojistas. Além dos materiais, a programação da produção também envolve a "organização da mão de obra, identificando gargalos de produção e necessidade ou não de novas contratações ou serviços externos" (TREPTOW, 2013, p. 185).

\title{
4.3.2 Ełapa 5 - Viabilização
}

\begin{abstract}
Nesta etapa, já sendo definida a proposta que atende as especificações, o produto é testado em situação real, junto a usuários. Somado a este são realizadas pesquisa (no exemplo de uma embalagem, podem ser realizados em pontos de venda), e junto a potenciais consumidores. Neste item podem ser utilizadas ferramentas de avaliação de ergonomia, usabilidade e qualidade aparente (MERINO, 2016, p. 14).
\end{abstract}

Para o desenvolvimento do produto de vestuário, esta etapa refere-se à avaliação final do produto, produção do mostruário, a fim de avaliar a qualidade de produção. A partir disso, são geradas as fichas técnicas definitivas e 
desenvolvem-se as orientações das peças (etiquetas). A Figura 12 aborda a síntese da etapa 5 viabilização.

Figura 12. Momento Implementação - Etapa 5 - Viabilização.

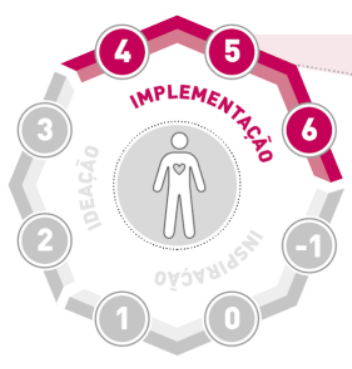

\section{VIABILIZAC̣Ão}

\begin{tabular}{|c|c|c|}
\hline O QUE É? & O QUE FAZER? & COMO FAZER? \\
\hline \multirow{3}{*}{$\begin{array}{l}\text { Verificações } \\
\text { finais e } \\
\text { Viabilização } \\
\text { da produção. }\end{array}$} & - Testar as peças. & - Provas em manequins estáticos ou modelos. \\
\hline & $\begin{array}{l}\text { - Indicar recomendações } \\
\text { gerais. }\end{array}$ & $\begin{array}{l}\text { Realizar as fichas técnicas finais, apresentando: } \\
\text { (desenho técnico, materiais utilizados, sequência } \\
\text { operacional da costura e os acabamentos } \\
\text { necessários). }\end{array}$ \\
\hline & - Acompanhar a produção. & $\begin{array}{l}\text { Acompanhar as peças; } \\
\text { Avalias as fotos do catálogo, quanto a coerência } \\
\text { com tema, cores e formas. }\end{array}$ \\
\hline
\end{tabular}

Fonte: Elaborada pelos autores (2019).

Nesta etapa o projeto entra em fase final de detalhamento por meio das seguintes ações: (1) avaliações técnicas e comerciais; (2) correções e adequações; (3) graduação da modelagem; (4) confecção da ficha técnica definitiva e da peça piloto; (5) Aquisição de matéria prima e aviamento; (6) definições de embalagens e materiais de divulgação. Todas essas ações culminam na produção seriada (MONTEMEZZO, 2003).

Após a prova das peças, realizadas em manequins de modelagem ou modelos de prova, faz se às correção e adequação dos protótipos. Assim que um protótipo é aprovado para a coleção, se faz a graduação (acrescentar ou diminuir a diferença proporcional às medidas de um manequim para o outro) dos moldes desta peça, ou seja, se produz os moldes nos outros tamanhos. A partir dessa graduação é possível realizar a simulação do encaixe ou o risco de corte (TREPTOW, 2013).

Neste momento desenvolve-se o mostruário, ou seja, o conjunto das réplicas de todos os protótipos que compõem a 
coleção. Para produzir o mostruário o designer escolhe em qual das variantes de cor disponíveis cada peça será reproduzida. Todas as peças do mostruário devem conter uma etiqueta com as seguintes informações: referência do modelo, tecido e composição, variantes de cor, tamanho e preço (TREPTOW, 2013). É muito comum as empresas de confecções elaborarem um catálogo da coleção como forma de divulgar os produtos, e com todo o mostruário finalizado é possível realizar as fotos do catálogo. Neste momento todas as peças são provadas por modelos e fotografadas em forma de conjuntos ou look, e então uma nova avaliação geral da coleção pode ser feita, com sugestão de alterações que podem ser necessárias se a coleção como um todo foge à ideia original, ou se o conjunto não tem unidade em termos de cor, tipo de roupa ou tecido (RENFREW; RENFREW, 2010).

\subsubsection{Ełapa 6 - Verificação Final}

Todo projeto deveria considerar os aspectos de sustentabilidade, focado no destino dos produtos após o término do tempo de vida útil, seu impacto econômico e social. Esta etapa é considerada de vital importância, no sentido que poderá gerar novas oportunidades, permitindo desta forma uma retroalimentação do percurso do design. Em suma, um novo ponto de partida, rompendo (sutilmente) com o pensamento de linearidade, num processo caracterizado por (pequenos) passos rumo à um pensamento sistêmico (MERINO, 2016, p. 14).

Para o desenvolvimento do produto de vestuário, esta etapa refere-se ao acompanhamento e verificação da comercialização da coleção, que normalmente ocorre junto aos representantes comerciais e clientes lojistas. Ainda por se tratar de uma metodologia centrada no usuário, se faz 
relevante buscar a interação com o consumidor (usuário) real das vestimentas. Após essa verificação, a partir dos comentários e feedbacks recebidos, é possível organizar a próxima coleção de maneira mais adequada às demandas. A Figura 13 aborda a síntese dessa etapa.

Figura 13. Momento Implementação - Etapa 6 - Verificação Final.

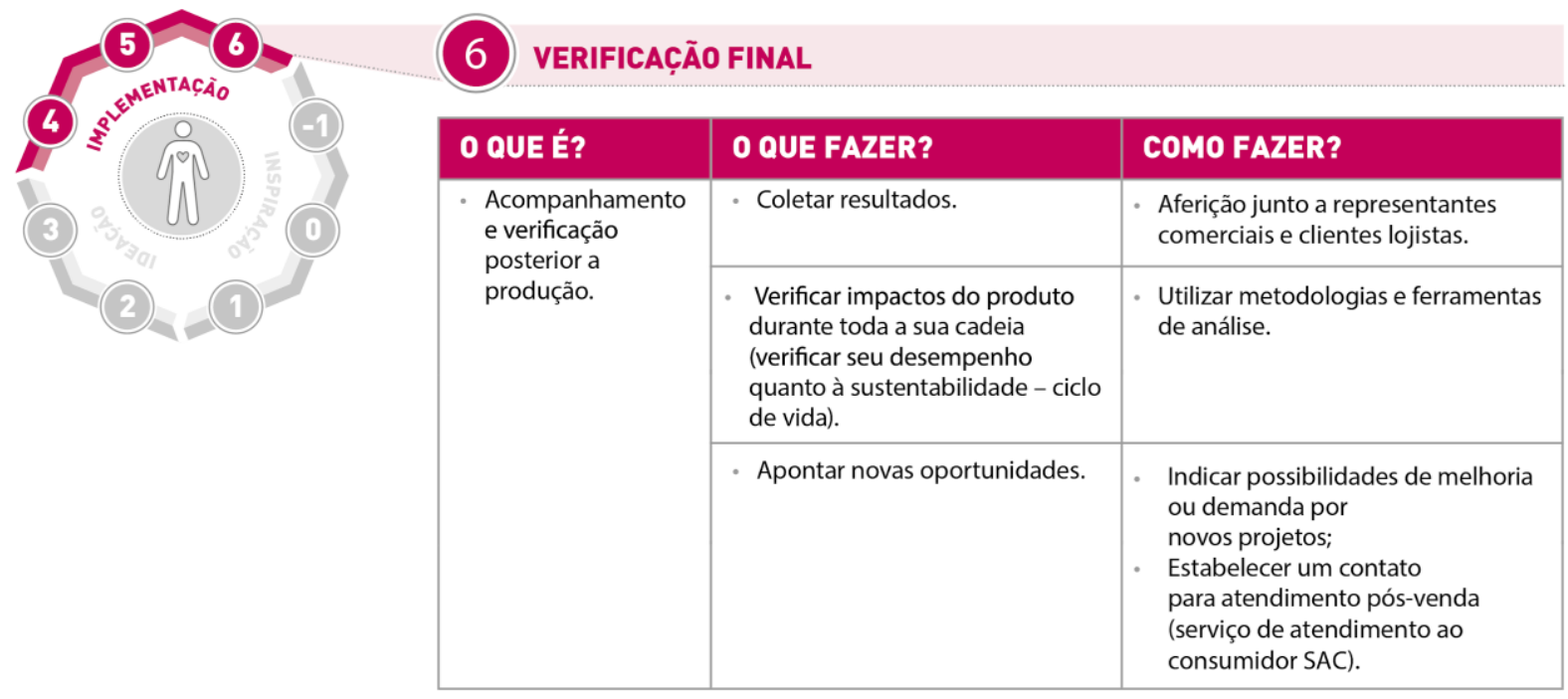

Fonte: Elaborada pelos autores (2019).

O lançamento e divulgação de uma coleção pode ocorrer por meio de participação em feiras do setor, realização de desfiles, e produção de catálogos. A comercialização pode ser no atacado, por meio de pedidos, à pronta-entrega, ou no varejo (TREPTOW, 2013).

Durante ou após a venda da coleção é importante realizar uma pesquisa de mercado, por meio de entrevistas informais com os consumidores. Nestas entrevistas sugere-se fazer algumas perguntas simples sobre a necessidade ou desejo de compra de determinada peça de vestuário, ou mesmo do que não foi encontrado no mercado, pois as respostas refletem as preferências dos consumidores por determinados estilo de roupas ou acessórios, cores e tamanhos, e auxiliam 
no desenvolvimento de novos produtos contemplando as necessidades e desejos dos consumidores (FRINGS, 2012). Também é possível obter informações importantes sobre a coleção por meio de conversas com os representantes, pois estes estão em contato direto com os clientes lojistas, além de possuírem informações sobre a coleção de concorrentes. Os representantes sugerem determinados tipos de peças para inserir na coleção, repassam informações sobre peças que não venderam de forma satisfatória, bem como informações sobre o que o cliente lojista pensa sobre a coleção no que tange a qualidade, beleza, conforto, investimento e retorno financeiro (MAKARA, 2017).

Treptow (2013) sugere a realização de uma reunião de feedback, durante ou após o período de comercialização da coleção, ou que também pode ocorrer concomitante à reunião de planejamento da nova coleção, pois o objetivo desta reunião de feedback é analisar os pontos positivos e negativos da última coleção, verificar os registros de vendas e as opiniões dos clientes.

\section{Conclusão}

Este artigo buscou aplicar o Guia de Orientação para o desenvolvimento de Projetos (GODP), na prática projetual do Design de Moda. Conclui-se que o objetivo foi alcançado, originando uma metodologia com abordagem centrada no usuário para o desenvolvimento dos produtos de vestuário. Compreende-se que o GODP aplicado à prática projetual do Design de moda, pode auxiliar os designers na compreensão das reais necessidades dos usuários, reconhecendo suas capacidades e limitações, fazendo com que os projetos sejam mais efetivos. 
Acrescenta-se ainda que o GODP aplicado a moda pode facilitar a gestão dos processos operacionais de desenvolvimento do produto de vestuário, melhorando os fluxos informacionais $e$, consequentemente na tomada de decisão projetual. Ademais, o objetivo do método, além de considerar o usuário como o ponto de partida, é garantir uma sistemática organizada e planejada, o que permite o levantamento, a organização e a análise dos dados consciente, fornecendo informações relevantes para o projeto, e assim consequentemente, favorece 0 direcionamento criativo e mercadológico no desenvolvimento do vestuário.

Convém destacar que esta estrutura didática, sistemática e organizada do GODP, é proveniente da utilização dos blocos de referência: Produto, Usuário e Contexto. Desta forma, desde o início do desenvolvimento do produto de vestuário, todas as informações podem ser divididas e organizadas dentro dos Blocos de Referência. Esta organização e sistematização favorece o desenvolvimento do produto de vestuário, visto que possibilita extrair e converter os dados em informações de projetos. Além disso, oportuniza agilidade e praticidade. Cabe ainda salientar a flexibilidade e adaptabilidade do método o que permite ajustes no seu processo de acordo com as particularidades de cada projeto.

Neste sentido, a metodologia proposta contribui com os projetistas (designers de moda), facilitando o PDP do vestuário, com a minimização de fragilidades no processo, referente ao levantamento, interpretação e a organização do grande volume de informações, favorecendo a visão panorâmica das informações durante o desenvolvimento do produto de vestuário, que considera o usuário do produto e seu contexto de uso. A metodologia proposta também 
contribui com o usuário final, haja visto que o GODP propõe sua consideração ao longo de todo o processo de desenvolvimento do produto. Assim, é possível afirmar que o método permite atender as expectativas dos usuários, no que tange ao conforto, segurança e usabilidade das vestimentas, afinal o vestuário, deve ser confortável e funcional.

Sobre as contribuições científicas e sociais, esta pesquisa, ao ser inserida no ambiente empresarial pode favorecer a oferta de produtos de vestuário no mercado com maior qualidade e inovação, bem como, colaborar com o aumento das vendas. Assim, ressalta-se que os usuários também são beneficiados com a pesquisa ao poder encontrar produtos mais adequados às suas necessidades. Desta maneira reafirma-se a importância e relevância da moda e design para a sociedade.

Por fim, estudos já estão sendo realizados com a aplicação do GODP em contexto real, tanto no meio acadêmico (projetos de conclusão de curso, mestrado e doutorado) como no ambiente empresarial. Além disso, podem ser realizadas futuras pesquisas de ferramentas que possam ser acrescentadas as etapas do GODP para auxiliar na prática projetual, desde a fase inicial de construção de painéis semânticos, levantamento de dados com usuários, até mesmo ferramentas para a consideração dos fatores humanos na criação e modelagem.

\section{Referências}

ANDRADE, Allisson José Fernandes de. Dispositivo auxiliar à abertura de latas direcionado a usuários com artrite reumatoide. 2018. 143 f. TCC (Graduação) - Curso de Design, Universidade Federal de Santa Catarina, Florianópolis, 2018.

BACK, Nelson et al. Projeto integrado de produtos: planejamento, concepção e modelagem. Barueri - São Paulo: Manole, 2008. 
BLUM, Arina. Gestão de design na prevenção do erro de medicação: ações para uma farmácia hospitalar. 2018. 325 f. Tese (Doutorado em Design) - Programa de Pós-Graduação em Design, Universidade Federal de Santa Catarina. Florianópolis, 2018.

BOUERI, J. J. Sob medida: antropometria, projeto e modelagem. In: PIRES, D.B. Design de Moda: olhares diversos. Barueri: Editora Estação das Letras e Cores, 2008, p. 347- 370.

CUNHA, Julia Marina. Design para inclusão: $O$ aparelho auditivo como acessório de moda. TCC (Graduação) - Curso de Design, Universidade Federal de Santa Catarina, Florianópolis, 148 p., 2017.

DISITZER, Marcia. VIEIRA, Silvia. A moda como ela é. bastidores, criação e profissionalização. Rio de Janeiro: Senac Nacional, 2006.

FERNANDES, Diego Sanches. Proposta de modelo de processo de desenvolvimento de produtos para indústria do vestuário de moda de micro e pequeno porte. 2013. $133 \mathrm{f}$. Dissertação (Mestrado) - Curso de Engenharia de Produção, Setor de Tecnologia, Universidade Federal do Paraná, Curitiba, 2013.

FERNÁNDEZ, Ángel. ROING, Gabriel Martín. Desenho para designers de Moda. Editora Estampa, Lisboa, 2007.

FRINGS, Gini Stephens. Moda: do conceito ao consumidor. Porto Alegre: Bookman, 2012.

GARCIA, Lucas José. Modelo produto-usuário: Uma Ferramenta de Avaliação da Adequação Produto-Usuário para Gestão de Projetos. 2017. 234 f. Tese (Doutorado em Design) - Programa de Pós-Graduação em Design, Universidade Federal de Santa Catarina. Florianópolis, 2017.

HINNIG, Renata. Gestão de design e design de serviços: diagnóstico do setor de internação (emergência) de um hospital psiquiátrico. 2018. 203 f. Dissertação (Mestrado em Design) Programa de Pós-Graduação em Design, Universidade Federal de Santa Catarina. Florianópolis, 2018.

IIDA, Itiro; GUIMARÃES, Lia Buarque de Macedo. Ergonomia: projeto e produção. 3.ed. São Paulo: Blucher, 2016.

JONES, S. J. Fashion Design: manual do estilista. São Paulo: Editora Cosac Naify, 2005.

LAKATOS, Eva Maria; MARCONI, Marina de Andrade. Fundamentos de metodologia científica. 6. ed. São Paulo: Atlas, 2011.

MAKARA, Elen. Gestão de Design em Micro e Pequenas Empresas de Confecção do Município de Gaspar/SC: $O$ Processo de Desenvolvimento de Produto ede Vestuário e a Consideração do Usuário. 2017. 162 f. Dissertação (Mestrado) Curso de Design, Universidade Federal de Santa Catarina, Florianópolis, 2017. 
MARTINS, S. B. Ergonomia e moda: repensando a segunda pele. In: PIRES, D.B. Design de Moda: olhares diversos. Barueri: Editora Estação das Letras e Cores, 2008, p. 319 - 336.

MEADOWS, Toby. Como montar e gerenciar uma Marca de Moda. Porto Alegre. Bookman, 2013.

MERINO, Giselle Schmidt Alves Díaz. Metodologia para a prática projetual do design: com base no Projeto Centrado no Usuário e com ênfase no Design Universal. 2014. 212 f. Tese (Doutorado em Design) - Programa de Pós-Graduação em Engenharia de Produção, Universidade Federal de Santa Catarina. Florianópolis, 2014.

MERINO, Giselle Schmidt Alves Díaz. GODP - Guia de Orientação para Desenvolvimento de Projetos: Uma metodologia de Design Centrado no Usuário. Florianópolis: NGD/UFSC, 2016. Disponível em: https://ngdldu-ufsc.squarespace.com/godplivro/. Acesso em: 5 abr. 2019.

MONTEMEZZO, Maria Celeste de Fátima Sanches. Diretrizes metodológicas para o projeto de produtos de moda no âmbito acadêmico. 2003. 98 f. Dissertação (Mestrado) - Curso de Desenho Industrial, Universidade Estadual Paulista Faculdade de Arquitetura, Artes e Comunicação, Bauru, 2003.

PICHLER, Rosimeri Franck. User-Capacity Toolkit: conjunto de ferramentas para guiar equipes multidisciplinares nas etapas de levantamento, organização e análise de dados em projetos de Tecnologia Assistiva. 2019. 297 f. Tese (Doutorado em Design) Programa de Pós-Graduação em Design, Universidade Federal de Santa Catarina. Florianópolis, 2019.

RECH, Sandra Regina. Moda: por um fio de qualidade. Florianópolis: Udesc, 2002.

RENFREW, Elionor. RENFREW Colin. Desenvolvendo uma coleção. Porto Alegre: Bookman, 2010.

ROSA, Carolina Schütz. Design e tecnologia assistiva: desenvolvimento de dispositivo auxiliar de marcha para usuário com limitação motora. 2017. 129 f. TCC (Graduação) Curso de Design, Universidade Federal de Santa Catarina, Florianópolis, 2017.

SANCHES, M. C. F. Projetando moda: diretrizes para a concepção de produtos. In: PIRES, D.B. Design de Moda: olhares diversos. Barueri: Editora Estação das Letras e Cores, p. 289-302, 2008.

SAMPIERI, Roberto Hernández; COLLADO, Carlos Fernández; LUCIO, María del Pilar Baptista. Metodologia de pesquisa. 5. ed. Porto Alegre: Penso, 2013.

SEIVEWRIGHT, Simon. Pesquisa e design - 2 ed. Porto Alegre: Bookman, 2015.

TAKAYAMA, Leticia. Desenvolvimento de um calçado para mulheres com hálux valgo (joanete). 173 f. TCC (Graduação) - Curso de Design, Universidade Federal de Santa Catarina, Florianópolis, 2017. 
TREPTOW, Doris. Inventando moda: planejamento de coleção. Doris Treptow -5 ed. São Paulo: Edição da autora, 2013.

VARNIER, Thiago. Fatores Humanos associados aos projetos de Design: protocolo de coleta para a captura de movimentos. 250 f. Dissertação (Mestrado em Design) - Programa de Pósgraduação em Design, Universidade Federal de Santa Catarina, Florianópolis, 2019.

VARNIER, Thiago; MERINO, Eugenio Andrés Díaz. Fatores humanos aplicados a produtos de moda: materiais têxteis com termorregulação voltados ao público idoso. Human Factors in Design, v. 6, n. 11, p. 72-89, 2017.

VICENTINI, Cláudia Regina Garcia. Ferramentas e metodologia de projeto aplicados na criação de produtos para a indústria têxtil-confecção. 2010. 157 f. Tese (Doutorado) Curso de Engenharia Mecânica, Projeto Mecânico, Universidade Estadual de Campinas Faculdade de Engenharia Mecânica, Campinas, 2010. 